Національний університет кораблебудування імені адмірала Макарова ORCID: 0000-0003-2186-9488

С.P. СЕЛІВЕРСТОВА

Херсонська державна морська академія ORCID: 0000-0003-1015-1593

I.А. ССЛІВЕРСТОВ

Херсонський національний технічний університет

\title{
УТОЧНЕННЯ КРИТЕРІЮ БЕЗПЕКИ ПРИ АНАЛІЗІ РОЗВИТКУ РОЗРЯДНИХ ПРОЦЕСІВ В ТЕХНОЛОГІЇ ЗАПОВНЕННЯ НАФТОПРОДУКТАМИ ОБ'СМІВ
}

У статті проведений аналіз вибору критерію безпеки технологї транспортування слабкопровідних заряджених рідин (СПЗР) в замкнуті об'єми. Така технологія, має регулюючі елементи $i$ завжди містить аналіз якого-небудь параметра, як критерій технології, шьо обслуговується. Дана технологія вимагає точності діагностування, оскільки пов'язана з фізичними прочесами генерації заряду статичної електрики в устаткуванні. Вимога точного діагностування иієї величини ставить перед розробником завдання вибору оптимального критерію - вимірюваного параметра, за яким генерується реальна величина управління параметрами технології транспортування при зміні лінійних розмірів об'єкту діагностування $i$ відстані від датчика до точок діагностики. Прочес діагностування накопичення енергї електростатичного поля у танку, стає вирішальним, при застосуванні різних режимів заповнення потоку нафтопродуктів. Оскільки аналізу і виміру піддається динамічний рух зарядів рідини, то слід аналізувати квазістатичне поле, щзо містить нерівномірний розподіл зарядів.

Моделювання показує необхідність уточнення критерію аналізу розвитку розрядних властивостей на поверхні слабко-провідних заряджених рідин в замкнутій, екранованій системі. Підхід, що пропонується, спрощено реалізує розташування устаткування і отримання даних для управління системою заповнення об'ємів. Сучасний критерій безпеки, потенціал $\varphi$ поверхні слабко-провідних заряджених рідин, має складність в реалізащії, завдяки хвилюванню поверхні рідини, великій площчі поверхні діагностування, глибині заповнення і віддаленості точок діагностування від датчиків. Новий підхід вимагає розробки нового методу або математичної моделі, де для кожного з нафтопродуктів, щзо транспортуються, будуть створені відповідні технічні або модельні засоби, щзо дозволяють визначити максимально безпечні параметри напруженості $E_{n}$ поля замкнутого об'єму. Розробка, моделювання і конструювання потребують створення діагностики саме динамічної (квазістатичною) форми поля, щуо повинно бути пов'язано з фізичною моделлю поглинання і виділення енергї̈ об'єму слабкопровідних заряджених рідин.

Ключові слова: слабко-провідні заряджені рідини, критерій безпеки, квазістатичне поле, напруженість, замкнута екранована система.

О.Л. КИРИЛЛОВ

Национальный университет кораблестроения имени адмирала Макарова ORCID: 0000-0002-8021-6340

А.Н. ФРОЛОВ

Национальный университет кораблестроения имени адмирала Макарова ORCID: 0000-0003-2186-9488

С.Р. СЕЛИВЕРСТОВА

Херсонская государственная морская академия ORCID: 0000-0003-1015-1593

И.А. СЕЛИВЕРСТОВ

Херсонский национальный технический университет

\section{УТОЧНЕНИЕ КРИТЕРИЯ БЕЗОПАСНОСТИ ПРИ АНАЛИЗЕ РАЗВИТИЯ РАЗРЯДНЫХ ПРОЦЕССОВ В ТЕХНОЛОГИИ ЗАПОЛНЕНИЯ НЕФТЕПРОДУКТАМИ ОБЪЕМОВ}

В статье проведен анализ выбора критерия безопасности технологии транспортирования слабо-проводящих заряженных жидкостей (СПЗЖ) в замкнутые объемы. Такая технология, имеет регулирующие элементы и всегда содержит анализ какого-либо параметра, в качестве критерия обслуживаемой технологии. Рассматриваемая технология требует точности диагностирования, 
поскольку связана с физическими прочессами генерации заряда статического электричества в оборудовании. Требование точной диагностики этой величины ставит перед разработчиком задачу выбора оптимального критерия - измеряемого параметра, по которому генерируется реальная величина управления технологией транспортировки при изменении линейных размеров объекта диагностирования и расстояния от датчика до точек диагностики. Процесс диагностирования накопления энергии электростатического поля в танке становится решающим при применении различных режимов заполнения потока нефтепродуктов. Поскольку анализу и измерению подвергается динамическое движение зарядов жидкости, то следует анализировать квазистатическое поле, содержащее неравномерное распределение зарядов.

Моделирование показывает необходимость уточнения критерия анализа развития разрядных свойств на поверхности слабо-проводящих заряженных жидкостей в замкнутой, экранированной системе. Подход упрощенно реализует расположение оборудования и получение данных для управления системой заполнения. Современный критерий безопасности, потенциал $\varphi$ поверхности слабопроводящих заряженных жидкостей, имеет сложность в реализаџии, благодаря волнению поверхности жидкости, большой площзди поверхности диагностирования, глубине заполнения и удаленности точек диагностирования от датчиков. Новый подход требует разработки нового метода или математической модели, где для каждого из транспортируемых нефтепродуктов будут созданы соответствующие технические или модельные средства, позволяющие определить максимально безопасные параметры напряженности $E_{n}$ поля замкнутого объема. Разработка, моделирование и конструирование потребуют создания диагностики именно динамической (квазистатической) формы поля, что должно быть связано с физической моделью поглощения и выделения энергии объема слабопроводящих заряженных жидкостей.

Ключевые слова: слабо-проводящฺих заряженных жидкостей, критерий безопасности, квазистатическое поле, напряженность, замкнутая экранированная система.

O.L. KIRILLOV National University of Shipbuilding named after Admiral Makarov ORCID: 0000-0002-8021-6340

A.N. FROLOV

National University of Shipbuilding named after Admiral Makarov ORCID: 0000-0003-2186-9488

S.R. SELIVERSTOVA

Kherson State Maritime Academy

ORCID: 0000-0003-1015-1593

I.A. SELIVERSTOV

Kherson National Technical University

\section{CLARIFICATION OF CRITERION OF SAFETY AT ANALYSIS OF DEVELOPMENT BIT PROCESSES IN TECHNOLOGY OF FILLING OIL PRODUCTS OF VOLUMES}

In the article the analysis of choice of criterion of safety of technology of portage of the liquid bad conducting $(L B C)$ in the reserved volumes. Such technology, has regulative elements and always contains the analysis of some parameter, as a criterion of the served technology. The examined technology requires exactness of diagnosticating, as related to the physical processes of generation of charge of static electricity in an equipment. The requirement of exact receipt of this size sets the problem of choice of optimal criterion before a developer - measureable parameter on which the real size of management technology of transporting at the change of linear sizes of object of diagnosticating and distance is generated from a sensor to the points of diagnostics. The process of diagnosing the accumulation of energy of the electrostatic field in the tank becomes decisive when using various modes of filling the flow of oil products. Since the dynamic motion of charges in a liquid is analyzed and measured, it is necessary to analyze a quasi-static field containing an uneven distribution of charges.

A design shows the necessity of clarification of criterion of analysis of development of bit properties on the surface of the liquid bad conducting in the closed, screened system. Approach simplified will realize the location of equipment and receipt of data for a management the system of filling. The modern criterion of safety, potential $\varphi$ of surface of the liquid bad conducting, has complication in realization, due to agitation, large area of surface of diagnosticating, depth of filling and remoteness of points of diagnosticating from sensors. New approach requires development of new method or mathematical model, where for each of transported нефтепродуктов соrresponding technical or model facilities, allowing to define the maximally safe parameters of tension $E_{n}$ of the field of the reserved volume, will be created. Development, design and constructing, will demand creation of diagnostics exactly of dynamic (quasi-static) form of the field, that it must be related to the physical model of absorption and selection of energy of volume of the liquid bad conducting. 
Keywords: the liquid bad conducting, criterion of safety, quasi-static field, tension, closed screened system

\section{Постановка проблеми}

Головна частина технології заповнення замкнутих об'ємів заряджаючими слабко-провідними рідинами (СПЗР), що відповідає за безпеку свого проведення, пов'язана 3 перевищенням накопичення енергії електростатичного поля в рідині і точного діагностування критерію, а тому вимагає аналізу i переосмислення виділеного критерію для оцінки працездатності технологічного циклу, який підвержений спостереженню. Залежно від алгоритму проведення цього процесу визначається ряд чинників, що впливають на працездатність технології, а також, найголовніше - безпека його проведення.

У основі технології транспортування заряджених рідин (СПЗР), що слабо-проводять, лежить неухильне дотримання технологічних режимів витрати $\mathrm{F}[1,2,3]$, яка призводить до накопичення в просторі СПЗР заряду, завдяки взаємодії рухомої речовини зі стінкою транспортного трубопроводу [4]. У заповнюваному об'ємі СПЗР накопичується заряд, який поступово зростає. Якщо не враховувати цього процесу накопичення, може статися процес мимовільного виділення накопиченої надлишкової енергії цього заряду на поверхні заповнюваної СПЗР на стінки танка у формі розряду $[1,2,3]$. Описаний стан в даній технології є перевищенням норм витрати, залежно від рівня заповнення [1,2] в результаті відхилення від програми затоки. Дані процеси виникають в результаті не лінійності функції $\mathrm{n} \cong \mathrm{f}(\mathrm{F})$ між обертами на валу насосів $n$ i їх величинами витрати $F$.

Таким чином, для цього технологічного процесу розробляють систему управління, яка хоч $\mathrm{i}$ справляється 3 поставленим запрограмованим завданням, проте, виникає необхідність в додатковій ланці - діагностичній, оскільки СПЗР - горючі рідини.

На "Міжнародній конференції із статичної електрики", в Лондоні [5], англійськими фізиками був сформульований критерій, що визначає безпеку процесу транспортування СПЗР. У якості критерію безпеки - був визначений потенціал поверхні СПЗР (області розділу просторів: пароповітряного (ПП) $\leftrightarrow$ (СПЗР), який прирівняли до величини $\varphi \leq 40$ кВ. При цьому гарантувалася відсутність і виникнення розряду, який запалює над поверхнею рідини пароповітряну суміш [5]. Аналіз і дослідження привели до зниження рівня критерію до величини $\varphi \leq 25$ кВ [2,3], виключивши неточності і похибки виміру в ході проведення операцій транспортування нафтопродуктів, використовуваних на нафтових підприємствах. Основним критерієм, яким користувалися на той момент часу була напруженість поля в центрі заповнюваного об'єму.

На тимчасовий момент ця характеристика виявилася параметром, який характеризує увесь шар діелектрика, а тому охоплює увесь спектр електричних процесів усередині речовини, у тому числі і вихід на поверхню енергії з нього, на відміну від потенціалу, який характеризує тільки плівку - результат на поверхні СПЗР. З'ясувалося також, що розподіл електростатичної енергії зарядів в заповнюваній в танках рідині нерівномірний, що потребує додаткового вивчення процесу.

Таким чином, процес вибору критерію безпеки даної технології переміщення нафти і нафтопродуктів з одного об'єму в іншій, представляє собою аналіз рівня безлічі різних параметрів, з яких вибирають інтегральну величину, яка найдостовірніше аналізує стан безпеки технологічного ланцюга переміщення рідкого вантажу.

Під безпекою даної технології розуміють стан накопичення електростатичного заряду в елементах устаткування, в яких здатна вивільнятися його електростатична енергія у вигляді розряду. Найбільш небезпечною областю для виділення розряду в технологічному процесі, знаходиться усередині заповнюваного об'єму (танка), над поверхнею рідкого вантажу, що транспортується в танк, нафтопродукту.

Явище розрядів, в даній області, зазвичай призводить до пожежі або вибуху [1-4], залежно від концентрації пари рідини в пароповітряному просторі над нею, ії температурою і стану вологості. Тому, процес діагностування накопичення енергії електростатичного поля у танку, стає вирішальним, при застосуванні різних режимів заповнення потоку нафтопродуктів. Оскільки аналізу і виміру піддається динамічний рух зарядів разом із СПЗР, що транспортується, то слід аналізувати квазістатичне поле, то - $\epsilon$ поле, що містить нерівномірний розподіл зарядів. Дане завдання ускладнено не лише аналізом вибраного критерію, але і самим вибором його, при проектуванні заповнюваних об'ємів, виходячи 3 можливостей конструкторської реалізації процесу діагностування.

Таким чином, рішення цієї складної задачі має розвиток напрямів в різних областях досліджуваної технології, але при цьому вимагається достовірність отриманого результату діагностування стану енергії квазістатичного поля, яка сигналізує відсутність стану вивільнення заряду накопиченої енергії в будь-якій точці поверхні заповнюваного нафтопродукту. Вибір критерію діагностування, а також, самого способу отримання стійкої величини діагностування, при транспортуванні рідкого заповнюваного нафтопродукту, привели до аналізу різних характеристик i властивостей квазістатичного поля. 
Математичні методи дискретизації процесу діагностування, на різних етапах руху СПЗР, що транспортується, привели до діагностики параметрів енергії поля кінцевої області переміщення рідкого нафтопродукту, тобто в танку. Таким чином, процес вибору критерію і його діагностики визначається аналізом кінцевої області транспортування нафтопродукту. Слід також пам'ятати про динаміку поширення заряду в досить великих об'ємах нафтопродукту, що породжують різні розподіли потенціалу на поверхні СПЗР, русі поверхневих і внутрішніх струмів в рідині, а також ії нагрів. Гідродинаміка рідини у великих об'ємах викликає поверхневе хвилювання, а тому, нестабільне діагностування потенціалу на поверхні, при використанні локальних датчиків, налаштованих на конкретну точку поверхні рідини.

Сукупність перерахованих чинників не лише впливає на результат діагностування, але і на складність конструювання активного елементу датчика, що розробляється, 3 отриманням точної реалізації виміру рівня критичної величини безпеки технології перекачування СПЗР.

Відсутність реалізації точного і гарантованого результату потенціалу поверхні СПЗР, в процесі заповнення замкнутих об'ємів нафтопродуктами, вимагає зміни парадигми в підході до діагностування критерію безпеки технології, що проводиться.

Динаміка зміни відстані від датчика до досліджуваної поверхні і квазістатичне поле, утворене нерівномірністю розподілу зарядів в шарах СПЗР, вимагають зміни підходу до процесу діагностики стану безпеки даної технології. З'явилася необхідність в дослідженні критерію заповнюваної СПЗР одночасно в декількох місцях їі заповнення, що було підказало не лише фізикою стану виникаючого поля, але і математичним описом досліджуваного простору.

Цей підхід дозволяє визначити стан розподілу енергії заповненого продукту і місць виходу ії до поверхні. У зв'язку з цим вимір дії динаміки внутрішніх енергетичних процесів, що відбуваються в СПЗР, і зміна їі лінійних параметрів при заповненні - вимагає аналізу поля усього об'єму рідини.

В результаті для цього, наприклад, підходить параметр діагностики, - напруженість $\bar{E}$ поля.

Виникнення інших величин, що характеризують поле, і їх отримання розглядається в роботах

Аналіз проведеної проблеми у введенні не дозволяє зупинитися на виборі конкретного параметра, вибраного як критерій, проте має можливість проаналізувати підхід до рішення задачі безпеки транспортування, при застосуванні діагностики параметра напруженості поля $\bar{E}$ при утворенні заповненням в танку структурою, яка складається з 2-х діелектриків. Тобто, розподіл зарядів генерують напруженості $\bar{E}_{1}$ i $\bar{E}_{2}$ у шарах пароповітряного простору і самої рідини, які впливають на тонку плівку поверхні нафтопродукту, викликаючи в ній розрядні явища.

Цей підхід більш точно і наочно описує фізику процесу утворення розрядних явищ на поверхні заповнюваної рідини і легше діагностуємо.

\section{Аналіз останніх досягнень і публікацій}

У статтях і науковому підході до досліджуваної проблеми [1-8] пропонований підхід до аналізу безпеки має ряд переваг і особливо при побудові засобів діагностування.

Раніше подібного підходу до проблеми безпеки не було, оскільки не розглядався взаємозв'язок понять заряд і спосіб його вивільнення з середовища у вигляді розряду.

Раніше в роботах $[2,3]$ передбачалося застосування одного датчика аналізу напруженості поля на увесь об'єм заповнюваної рідини, при цьому не розглядалося діагностика квазістатичної природи електромагнітного поля.

Даною вимірювальною характеристикою критерію безпеки, технологічного процесу транспортування СПЗР, що проводиться, найточніше може виступати тільки напруженість $\bar{E}$ досліджуваного поля, оскільки вимір може бути отриманий усередині будь-якого з діелектриків, а не на поверхні їх розділу.

Для вирішення цієї проблеми слід розділити простір діагностування на області і методом порівняння свідчень в різних областях вибрати найбільш високу величину, що характеризує критичне значення отриманого параметра 3 точки зору аналізу безпеки. Параметр знятий з цієї точки повинен характеризувати безпеку процесу. Величину досліджуваного критерію визначають по отриманих результатах проведених лабораторних досліджень стану поля в діелектрику, який складається з 2-х шарів і здатний ініціювати або генерувати розряд.

Розробка методу виміру напруженості $\bar{E}$ поля, в якості основного критерію безпеки, при транспортуванні СПЗР в замкнуті об'єми, виявилося досить ємкім завданням, оскільки вимагає додаткового дослідження у виді:

- проведення лабораторних випробувань і створення баз даних цих критичних значень композицій пар напруженості - $\bar{E}_{1}, \bar{E}_{2}$ при відповідних розмірах їх шарів або об'ємах (ПП) $\leftrightarrow$ (СПЗР), для кожного нафтопродукту;

- розробки методики виміру пропонованих параметрів поля; 
- розробки способів автоматизації процесу виміру і управління насосними установками.

\section{Формулювання мети дослідження}

Розробка методу виміру параметра, напруженості $\bar{E}$ поля, наближеного до реального результату, в процесі аналізу стану безпеки СПЗР, що транспортується, при різних режимах заповнення замкнутих об'ємів.

\section{Викладення основного матеріалу дослідження}

У разі нашого дослідження - спостерігається двошаровий діелектрик з різними властивостями $\varepsilon_{1}$ та $\varepsilon_{2}$, через області яких проходить нормальна складова електричної індукції $\bar{D}_{n}$ поля, енергія накопиченого електростатичного заряду в СПЗР [6,7]. Електрична індукція $\bar{D}_{n}$, проходячи обидва діелектрики, згідно співвідношення $\varepsilon_{1} E_{1}=\varepsilon_{2} E_{2}$, створює в діелектриках різні напруженості $E_{1} \neq E_{2}$, які впливають 3 обох сторін різних матеріалів на плівку поверхні СПЗР, створюючи в ній розрядні процеси, що призводять до появи і розвитку розрядів під час заповнення об'ємів, - що є наслідком небезпеки даної технології $[1,8,9]$.

Слід також враховувати зміну об'єму кожного з діелектриків в процесі заповнення, а зменшення об'єму діелектрика $V \downarrow \rightarrow$ веде до зниження електричної міцності області, яка екранована стінками резервуару, на які розвиваються розрядні процеси. При діагностуванні електричного стану фізичного процесу заповнення об'єму зарядженою рідиною, відповідає параметр напруженості поля $\bar{E}$ усередині діелектриків.

Також слід враховувати квазістатичне поле, тобто нерівномірність розподілу зарядів в заповнюваному об'ємі СПЗР - що відповідає нерівномірності розподілу заряду в рідині і відповідно до різної напруженості в різних точках заповнюваного простору. Звідки параметр, який гарантовано здійснюе повний аналіз стану діелектрика у квазістатичному полі, - напруженість $\bar{E}$ у різних його точках.

3 огляду на вищезазначені умови діагностування цього процесу слід проводити як різницю напруженості в областях досліджуваних діелектриків $E_{1}-E_{2} \neq 0$. Для охоплення досліджуваної області датчиками напруженості їх доцільно розмістити по крокам, утворюючи сітку точок розміщення на дні i даху об'єму (рис. 1), що відповідає математичному опису і аналізу стану процесу.

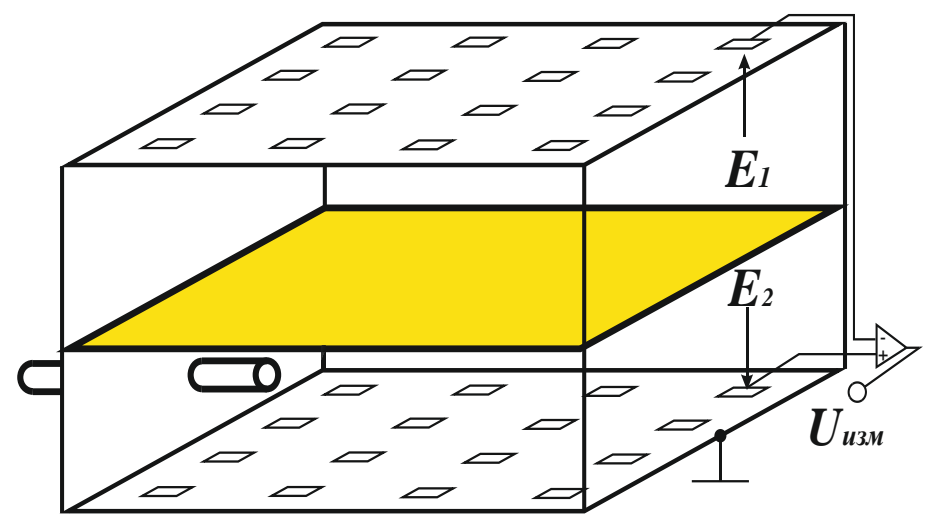

Рис. 1. Досліджувана область (об'єм)

Процес розробки і аналізу передбачуваного процесу діагностування вказує на необхідність в проведенні додаткового дослідження, що полягає в створенні стенду або математичної моделі за визначенням дії різних комбінацій напруженості $\left(\bar{E}_{1}, \bar{E}_{2}\right)$ на плівку поверхні різних СПзР при різних рівнях його заповнення.

Результат такого аналізу дає гарантоване розуміння дії напруженості на поверхню нафтопродукту, що дозволить створити лабораторну базу даних, на підставі яких можна стверджувати про стан розвитку розрядних явищ на поверхні СПЗР.

Оскільки на справжній момент процес діагностування здійснювати по потенціалу поверхні СПЗР скрутно, що пов'язано з додатковими розробками чутливих елементів діагностуючих приладів, згідно [7], має сенс змінити вимірюваний параметр (критерій) електростатичного поля - потенціал поверхні, на різницю напруженості $\Delta E=E_{1}-E_{2}$. Останній параметр точніше описує фізичний процес, оскільки оцінює усю енергію досліджуваної області в дотичних діелектриках і вказує на місце зосередження енергетичного сплеску - місця виходу енергії поля, місце розряду.

Сам критерій напруженості легко діагностувати за допомогою елементів Холу. Оскільки вони яквихідний сигнал мають постійну складову. Топологія розташування їх в заповнюваному об'ємі достатня на дні і даху заповнюваного простору, а електрична схема включення елементів - зустрічна, що дозволяє визначити величину напруженості $\Delta E=E_{1}-E_{2}$ у поверхневій плівці СПЗР. 
Для визначення максимально-безпечних значень напруженості в заповнюваному об'ємі слід розташувати датчики Холу попарно (дах-дно) з певним кроком розташування по осях X - Y паралельно площини розділу просторів СПЗР↔ПВ (рис.1).

Для знаходження точки виходу максимальної енергії $W_{\max }$ квазістатичного поля слід виробити комп'ютерний аналіз напруженості в усіх точках досліджуваного простору, знайти іiі максимальне значення $\Delta E_{\max }$ і порівняти його з базовою табличною характеристикою, отриманою в результаті досвідченої перевірки лабораторним чином безпосередньо на моделях або математичним аналізом електрофізичних властивостей СПЗР.

\section{Обговорення результатів}

Розглянутий аналіз пропонованого критерію, який діагностує фізичний процес заповнення замкнутого об'єму по параметру напруженості $E$ квазістатичного поля, показує наступне:

- здатність отримання реального результату досліджуваної величини в усьому заповнюваному об'ємі;

- отримання реальної картини безпеки без додаткових витрат на побудову i розробку спеціальних приладів і складання програм попереднього опису стану безпеки технологічного процесу заповнення;

- простоту проведення аналізу - методом періодичного діагностування показників датчиків , i порівняння серії свідчень з табличним значенням ;

- серія свідчень виявляє максимальне значення напруженості $\Delta E_{\text {max }}$ і області скупчення зарядів для розвитку розрядних явищ;

- пропонуємий шлях розвитку вимагає проведення досліджень нафтопродуктів на дію максимальної напруженості поля усередині замкнутого об'єму для отримання сімейства табличних значень критерію в плівці поверхні СПЗР, при визначенні стану безпеки технології заповнення.

\section{Висновки}

Результат проведеного аналізу показує уточнення критерію при розгляді розвитку розрядних явищ на поверхні СПЗР в замкнутій, екранованій системі, що складається 32 2-х діелектриків 3 різними властивостями і однаковим джерелом електростатичного поля у вигляді заряду, що накопичується, в доставленій в танк рідині.

Сучасний підхід у визначенні критерію безпеки через потенціал $\varphi$ поверхні СПЗР має складність в реалізації завдяки:

- хвилюванню СПЗР;

- великій площі поверхні діагностування;

- перепаді рівня рідини в танку в процесі заповнення;

- екранізації приладів у зв'язку з високим потенціалом усередині танка.

Альтернативний (запропонований) підхід дозволяє спрощено реалізувати діагностування 3 допомогою:

- розташування датчиків;

- отримання стійких даних для управління насосною установкою.

В той же час новий підхід вимагає розробки стенду або математичної моделі, де для кожного 3 нафтопродуктів, що транспортуються, будуть створені відповідні технічні або модельні засоби, що дозволяють визначити максимально безпечні параметри по напруженості $E_{n}$ даного поля замкнутого об'єму [10,11].

У додаванні до аналізу матеріалу технологія створення датчиків параметрів реалізації "потенційного напряму розвитку діагностики" даної технології, зажадає додаткових витрат для внесення змін до їх мікропроцесорної структури і конфігурації додаткових розробок програмного змісту, а також ускладнюючих засобів контролю і властивості захисту від силових полів.

Запропонована, альтернативна версія - вимагає тільки проведення серії дослідів в лабораторіях високої напруги, пов'язаної з різними нафтопродуктами для визначення і класифікації їх параметричних даних для порівняння [11].

\section{Список використаної літератури}

1. Кириллов О.Л. Исследование и автоматизация безопасного транспортирования нефтепродуктов: [Монография ч-І] / О.Л. Кириллов - Херсон: ХНТУ, 2017. - 413 с.

2. Галка В.Л. Электростатическая безопасность нефтеналивных судов и кораблей. / В.Л. Галка. - СПб.: Элмор. 1998. - 188c.

3. Максимов Б.К., Обух А. А., Тихонов А.В. Электростатическая безопасность при заполнении резервуаров нефтепродуктами. М.: Энергоатомиздат, 1989. - 154c.

4. Галка В.Л., Шигловский К.Б. Вопросы электростатической защиты танкеров // Судостроение. №10. 1993 г. 
5. Критерий электростатического воспламенения: материалы Международной конференции по статическому электричеству, Лондон, декабрь, 1977г.: Лондонский институт физики, 1977г. - 150с.

6. ОСТ 5. 6186-83. Защита нефтеналивных судов от статического электричества. Технические требования.

7. РД31. 81. 21. 94. Руководство по электрической безопасности нефтеналивных судов.

8. Галка В. Л. Техническая диагностика в задачах электростатической защиты грузовых систем нефтеналивных судов: Учеб. пособ. СПб. Академия судостроения. 1998 г.

9. Френкель Я.Н. К теории электрического пробоя в диэлектриках и электронных полупроводниках. ЖЭТВ. 1998. т.8.

10.Полянский В.А., Файззулин Р.Т., Панкратьева И.Л., Сахаров В.И. Численное моделирование электрогидродинамического течения слабопроводящей жидкости в канале при наличии инжекции заряда в поток // Доклады IV Международной конференции "Современные проблемы электрогидродинамики и электрофизики жидких диэлектриков". СПб.,1996. С. 121-129.

11. Миротворский В.О. Стишков Ю.К. Влияние приэлектродных реакций на распределение электрических характеристик системы электроды - жидкий диэлектрик (численный эксперимент) // Современные проблемы электрогидродинамики и электрофизики жидких диэлектриков: Тезисы докладов III Междунар. Конф. 28 июня - 1 июля. Петродворец. - СПб. 1994. с. 94.

\section{Referenses}

1. Kirillov O.L. Issledovaniye $\mathrm{i}$ avtomatyzatsiya bezopasnogo transportirovaniya nefteproductov: [Monografiya-ch-I]/ O.L. Kirillov . Kherson: HNTU, 2017. 413 p.

2. Galka V.L. Elektrostaticheskaya bezopasnost neftenalivnih sudov \& korabley. /V.L. Galka. SPb.: E'lmor. 1998. 188 p.

3. Maksimov B.K., Obuh A.A., Tihonov A.B. Elektrostaticheskaya bezopasnost pri zapolnenii rezervuarov nefteproductami. M.: Energoatomizdat. 1989. 154 p. №10. 1993.

4. Galka V.L., Sheglovskiy K.B. Voprosy elektrostaticheskoy zashity tankerov // Sudostroyeniye.

5. Kriteriy elektroctaticheskogo vosplameneniya: materialy Mezhdunarodnoy konferentzii po staticheskomu elektrichestvu, London, desember, 1977g.: Londonskiy institute fiziki, 1977. 150 p.

6. OST 5. 6186-83. Zashita neftenalivnih sudov ot staticheskogo elektrichestva. Tehnicheskiye trebovaniya.

7. RD31. 81. 21. 94. Rukovodstvo po elektricheskoy bezopasnosty neftenalivnih sudov.

8. Galka V.L. Tehnicheskaya diagnostika v zadachah elektrostaticheskoy zathity gruzovih system neftenalivnih sudov: Ucheb. posob. SPb. Akademiya sudostroeniya. 1998.

9. Frenkel Y.N. K teorii elektricheskogo proboya v dielektrikah I elektronnih poluprovodnikah. ZhETV. 1998. T.8.

10. Polyanskiy V.A., Fayzzulin R.T., Pankratyeva I.L., Saharov V.I. Chislennoye modelirovaniye elektrogidrodinamicheskogo techeniya ckfboprovodyashey zhidkosty v kanale pri nalichii inzhektziizaryadav potok // Doklady IV Mezhdunarodnoy konferentzii "Sovremenniye problem elektrogidrodinamiky I elektrofiziky zhidkih dielektrikov". StPetersburg, 1996. P. 121-129.

11. Mirotvorskiy V.O., Stishkov U.K. Vliyaniye prielektrodnih peaktziy na raspredeleniye elektricheskih harakteristik sistemy elektrody - zhidkiy dielektrik (chislenniy eksperiment) //Sovremenniye problemy elektrogidrodinamiki I elektrofiziki zhidkih dielektrikov: Tezisi dokladov III Mezhdunar. Konf. 28 iunya - 1 iulya. Petrdvoretzh. StPetersburg. 1994. P. 94. 